\title{
Application of a Rapid ESI-MS/MS Method for Quantitative Analysis of Docetaxel in Polymeric Matrices of PLGA and PLGA-PEG Nanoparticles through Direct Injection to Mass Spectrometer
}

\author{
Pedram Rafiei, Deborah Michel, Azita Haddadi* \\ Division of Pharmacy, College of Pharmacy and Nutrition, University of Saskatchewan, Saskatoon, Canada \\ Email: ${ }^{*}$ azita.haddadi@usask.ca
}

Received 19 December 2014; accepted 15 January 2015; published 20 January 2015

Copyright (C) 2015 by authors and Scientific Research Publishing Inc.

This work is licensed under the Creative Commons Attribution International License (CC BY). http://creativecommons.org/licenses/by/4.0/

(c) (1)

\section{Abstract}

Docetaxel is a member of taxan family of antineoplastic agents widely used in cancer chemotherapy. However, application of conventional chemotherapy with commercial formulation has been accompanied with matters of concern regarding drug's biodistribution, pharmacokinetics, and pharmacodynamics. Polymeric nanoparticles have been widely used as unique drug delivery vehicles to circumvent such problems. Docetaxel-loaded poly (lactide-co-glycolide) (PLGA) and poly (lactide-co-glycolide)-poly (ethylene glycol) (PLGA-PEG) nanoparticles fit well in modifying drug's pharmacokinetic characteristics as intravenous (IV) sustained-release delivery vehicles. In such circumstances, characterization of nanoparticles in terms of their drug-payload would be a necessary step. The majority of studies have used HPLC analysis method for docetaxel quantitation in polymeric nanoparticles. Herein, a rapid ESI-MS/MS method for quantitative analysis of docetaxel in polymeric matrices of PLGA and PLGA-PEG nanoparticles through direct injection to mass spectrometer has been developed and validated. The assay was validated over a range of 3.9 - 1000 $\mathrm{ng} / \mathrm{ml}$ and $125-16,000 \mathrm{ng} / \mathrm{ml}$. Samples were directly injected to the instrument through an isocratic elution $(0.1 \%$ formic acid in methanol) and detection was performed on a Hybrid Triple Quadrupole/Linear Ion trap mass spectrometer with multiple reaction monitoring (MRM) mode via positive electrospray ionization (ESI) source. The run time and retention time were 2 and 0.6 minutes respectively. The method demonstrated acceptable level of accuracy and precision and was successfully applied for quantitative analysis of docetaxel in polymeric nanoparticles of PLGA and PLGA-PEG.

\footnotetext{
${ }^{*}$ Corresponding author.
}

How to cite this paper: Rafiei, P., Michel, D. and Haddadi, A. (2015) Application of a Rapid ESI-MS/MS Method for Quantitative Analysis of Docetaxel in Polymeric Matrices of PLGA and PLGA-PEG Nanoparticles through Direct Injection to Mass Spectrometer. American Journal of Analytical Chemistry, 6, 164-175. http://dx.doi.org/10.4236/ajac.2015.62015 


\section{Keywords}

\section{Docetaxel, EI-MS/MS, Direct Injection, Multiple Reaction Monitoring (MRM), Positive Electrospray Ionization (ESI+), PLGA, PLGA-PEG}

\section{Introduction}

Docetaxel is a member of taxan family (antineoplastic agents) which exert their cytotoxic effects on microtubules [1]. It inhibits the disassembly of tubulin leading to inhibited cell division and cell death [2] [3]. Docetaxel has demonstrated antitumor activity in the treatment of patients with various cancer types [3]. Due to insolubility of the drug in water, a mixture of ethanol and tween 80 (polysorbate 80) has been used in the commercial docetaxel formulation $\left(\operatorname{taxoter}^{\circledR}\right.$ ) to enhancethe solubility [4]. There are issues associated with the medication, which are believed to be attributed to the formulation ingredients (ethanol/tween 80 ). These issues include hypersensitivity reactions, lower uptake by tumour tissue, and higher exposure of other body compartments to the drug [5] [6]. Meanwhile, alternate drug delivery systems such as polymeric nanoparticles have been invented to circumvent problems accompanied with docetaxel pharmacotherapy [7] [8]. Of these, poly (lactideco-glycolide) (PLGA)-made nanoparticles have been widely used to prepare spectacular drug delivery vehicles [9]. On the other hand, surface engineering of nanoparticles with poly (ethylene glycol) (PEG) has been effective to enhance blood circulation and delivery efficiency of PLGA nanoparticles [10] [11].

To have a thorough understanding of particle's drug-loading characteristics, the amount of drug inside nanoparticles must be quantitatively determined through an accurate, sensitive, precise, and reproducible analysis method. Various analytical methods have been developed to quantitatively evaluate docetaxel in polymeric matrices. The majority of studies have characterized drug loading properties benefiting from High performance liquid chromatography (HPLC) [12]-[17] while a few have applied UV method [18]. However, establishing a proper liquid chromatographic method would be at the expense of many resources. In some cases, it requires long separation times, even if additional techniques such as temperature-programed or gradient elution are used. Therefore, there is a need for a simple and rapid method, which permits fast screening of samples in polymeric matrices. There are several reports of docetaxel being quantified in biological matrices using either HPLC-UV [19] [20] alone or HPLC coupled to mass spectrometer [21]-[30]. However, LC-MS/MS represents to be the preferred analytical instrument to quantitatively analyse drugs in various matrices due to the inherent specificity and sensitivity. To further speed-up the quantitative analysis, the LC step can be omitted from the procedure. There are various examples of analysis techniques demonstrating application of mass spectroscopy without liquid chromatography [31]-[34]. Accordingly, direct injection to mass spectrometer can be considered an alternative to LC and MS coupled methods [35] [36].

In our study we have developed a method for rapid quantification of docetaxel in PLGA and PLGA-PEG polymer matrices in the form of nanoparticles. This technique relies on a simple solid phase extraction technique followed by positive electrospray ionization-tandem mass spectrometry detection without involvement of any chromatographic method for quantification of docetaxel in drug loaded nanoparticles.

\section{Materials and Methods}

\subsection{Materials}

Poly (D,L-lactide-co-glycolide) (PLGA) (50:50) with terminal carboxylate groups (PLGA, inherent viscosity $0.18 \mathrm{dl} / \mathrm{g}$ in hexafluoroisopropanol) was purchased from Absorbable Polymers International (Pelham, AL, USA). Poly (D,L-lactide-co-glycolide)-poly(ethylene glycol) (PLGA-PEG) di-block co-polymer (50:50 PLGA attached to mPEG 5000, 15\% wt) was obtained from Evonik Degussa Corp (Birmingham, AL, USA). Docetaxel and paclitaxel were purchased from LC laboratories (Woburn, MA, USA). All reagents were analytical grade or above and used as received, unless otherwise stated.

\subsection{Nanoparticle Preparation}

Nanoparticles were prepared from PLGA and PLGA-PEG polymers using a modified emulsification solvent 
evaporation technique established in our lab. Briefly, the polymer was dissolved in ethyl acetate $(10 \% \mathrm{w} / \mathrm{v})$ and added into a 2.2\% (w/v) PVA solution. The mixture was then vigorously shaken and subjected to high energy ultrasonication. The resulting nanosuspension was then subjected to stir for 2 hours to let the organic solvent evaporate. The nanoparticles were ultimately obtained after consecutive ultracentrifugation/washing steps. The obtained nanoparticles were finally resuspended in $1 \%$ sucrose aqueous solution and freeze-dried. The freezedried nanoparticles were stored at $-20^{\circ} \mathrm{C}$ for further use. Docetaxel-loaded PLGA or PLGA-PEG nanoparticles were prepared using different concentrations of drug through the same preparation approach. The various concentrations of $0.25,0.5,1$, and $1.5 \mathrm{mg} / \mathrm{ml}$ docetaxel solution were prepared in ethylacetate along with the polymer.

\subsection{Sample Preparation for Mass Spectrometry}

A stock solution of $100 \mu \mathrm{g} / \mathrm{ml}$ docetaxel was prepared by dissolving proper amount of drug in methanol and stored in $-20^{\circ} \mathrm{C}$ for further use. Working solution concentrations of 3.9, 7.8, 15.6, 31.2, 62.5, 125, 250, 500, $1000,2000,4000,8000$, and $16,000 \mathrm{ng} / \mathrm{ml}$ were prepared by further dilution (serial) of the stock solution with methanol. A stock solution of paclitaxel in methanol as internal standard was also prepared at $100 \mu \mathrm{g} / \mathrm{ml}$.

\subsection{Preparation of Standards, Controls and Test Samples}

To prepare polymer-free standards (docetaxel in methanol), $10 \mu \mathrm{l}$ of internal standard along with $1 \mathrm{ml}$ of working solution (3.9 - $1000 \mathrm{ng} / \mathrm{ml})$ were transferred into $2 \mathrm{ml}$ tubes and vortexed. Polymer-free controls were prepared as such to obtain $100,200,400$, and $800 \mathrm{ng} / \mathrm{ml}$ docetaxel concentrations. To prepare standard samples of nanoparticle formulations, $10 \mu \mathrm{l}$ of internal standard along with $1 \mathrm{ml}$ of working solution $(125-8000 \mathrm{ng} / \mathrm{ml}$ and 125 - 16,000 ng/ml for PLGA-PEG and PLGA nanoparticles respectively) were transferred into $2 \mathrm{ml}$ tubes and vortexed. The solvent was then evaporated and $5 \mathrm{mg}$ plain (drug-free) nanoparticles were added to the tube. Concentration set of 1250, 2500, 5000, and 10,000 ng/ml was used to prepare quality control samples of PLGA nanoparticles. This is while $625,1250,2500$, and $5000 \mathrm{ng} / \mathrm{ml}$ concentration set was used to prepare quality control samples of PLGA-PEG nanoparticles. $10 \mu \mathrm{l}$ of internal standard was added to control samples of PLGA or PLGA-PEG nanoparticles and vortexed. The solvent was evaporated and $5 \mathrm{mg}$ plain nanoparticle was added to the tube. To prepare test samples, $10 \mu \mathrm{l}$ of paclitaxel solution was added to $2 \mathrm{ml}$ tubes along with $5 \mathrm{mg}$ of drug loaded PLGA or PLGE-PEG nanoparticles. Standard, control, and test samples were extracted twice with acetone.

\subsection{Drug Extraction, Loading and Encapsulation Efficiency}

Docetaxel was extracted from PLGA or PLGA-PEG nanoparticles as follows. $1 \mathrm{ml}$ acetone was added to $5 \mathrm{mg}$ drug-loaded nanoparticles to dissolve both polymer and drug. The mixture was vortexed for 30 seconds and subjected to bath sonication for 30 minutes. Then it was centrifuged for 20 minutes at 20,000 g. The supernatant was separated and preserved. The precipitate was then dissolved in acetone and the same procedure was repeated. Obtained supernatants from the first and second centrifugation step were mixed and evaporated. $1 \mathrm{ml}$ methanol was added to the residue, vortexed for 30 seconds and centrifuged for 20 minutes at 20,000 g. Docetaxel was then quantified in supernatant using mass spectrometry method.

Yield of the preparation method, drug loading, and encapsulation efficiency of nanoparticles were calculated as follows:

Yield $(\%)=($ weight of obtained particles/initial weight of polymer, drug and other ingredients $) \times 100$

Drug loading $(\%)=($ weight of drug in particles/weight of particles $) \times 100$

Encapsulation efficiency $(\%)=($ weight of drug in particles/initial weight of drug added $) \times 100$

\subsection{Mass Spectrometric Conditions}

\section{Determination of MS/MS Fragmentation Patterns}

Docetaxel and paclitaxel were solubilized $(10 \mu \mathrm{g} / \mathrm{mL})$ in methanol containing $0.1 \%(\mathrm{v} / \mathrm{v})$ formic acid. Solutions were directly infused into the ionization source using a model 11 plus syringe pump (Harvard Apparatus, MA, USA) at a flow rate of $10 \mu \mathrm{L} / \mathrm{min}$ into a Hybrid Triple Quadrupole/Linear Ion trap mass spectrometer (AB Sciex 4000 QTRAP MS/MS system, Framingham, MA, US). The Turbo Ion-spray source was set to 5500 volts. Cur- 
tain gas, nebulizer, and heater gas pressure were 30,40 , and 40 psi respectively. The de-clustering potentials (DP) of docetaxel and paclitaxel were 46 and 55 respectively. Collision energys for docetaxel and paclitaxel were set to be 21 and 93 respectively. Collision cell exit potential was adjusted to 18 for both materials. Other instrument parameters include: interface heater $=\mathrm{ON}\left(150^{\circ} \mathrm{C}\right)$, collisionally activated dissociation $(\mathrm{CAD})=5$, and exit potential $=10$. Ultimately, precursor ion scans $(\mathrm{MS} / \mathrm{MS})$ were performed using positive electrospray ionization (+ESI) with appropriate set mass. According to the obtained pattern of docetaxel and paclitaxel fragmentation, suitable fragments were chosen and used in MRM transitions. Injection of samples (10 $\mu$ l) into the mass spectrometer was done using an Agilent Quaternary pump (1200 series) and Agilent G1329A (1200 series) auto sampler (Santa Clara, CA, USA) through a pre-column guard (Eclipse XDB-Rapid resolution, C18, $2.1 \times$ $30 \mathrm{~mm}, 3.5 \mu$, Agilent, Santa Clara, CA, USA) with a mobile phase flow rate of $200 \mu \mathrm{l} / \mathrm{min}$ (methanol, $0.1 \%$ formic acid, isocractic elution). Quantitation procedure was performed on corresponding docetaxel and internal standard MRM Graphs using Analyst software version 1.6.

\subsection{Method Validation}

\subsubsection{Determination of Limits of Detection and Quantitation}

Limit of Detection (LOD) and limit of quantitation (LOQ) of docetaxel in methanol, PLGA nanoparticles, and PLGA-PEG nanoparticles were measured based on a signal-to-noise ratio of respectively 3:1 and 10:1 with acceptable precision and accuracy.

\subsubsection{Linearity}

Standard samples of docetaxel in methanol, PLGA nanoparticles, and PLGA-PEG nanoparticles were prepared as described previously, extracted and subjected to mass spectrometer for analysis. Linear regression analysis was carried out on known added concentrations of docetaxel (weighted 1/x) against the peak area ratio of docetaxel to internal standard. Then, regression coefficient $\left(\mathrm{R}^{2}\right)$, slope, intercept, and equation of the resulting standard curves were determined.

\subsubsection{Method Precision}

Quality control samples as lower limit of quantitation (LLOQ), low quality control (LQC), middle quality control (MQC), and high quality control (HQC) were prepared for samples of docetaxel in methanol, PLGA nanoparticles, and PLGA-PEG nanoparticles as described and injected to the mass spectrometer $(n=6)$. The coefficient of variations (CV\%) of the corresponding concentrations were determined in each case.

\subsubsection{Method Accuracy}

Quality control samples were prepared for samples of docetaxel in methanol, PLGA nanoparticles, and PLGAPEG nanoparticles as described and subjected to the mass spectrometer analysis $(n=6)$. Accuracy of the method was determined as the ratio of the measured concentration (based on standard curve) to the corresponding added (nominal) concentration.

\section{Results and Discussion}

\subsection{Mass Spectrometry}

Positive ESI tandem mass spectra of docetaxel $(809.4 \mathrm{~m} / \mathrm{z})$ and paclitaxel $(855.2 \mathrm{~m} / \mathrm{z})$ are shown in Figure 1 and Figure 2 respectively. Large abundance of the parent ion was observed in the MS/MS spectra of both materials as protonated entities $\left([\mathrm{M}+\mathrm{H}]^{+}\right)$. The proposed fragmentation pattern of each compound is also provided in upper right hand section of the figures. As exhibited in Figure 1, six product ions of docetaxel demonstrated high intensities. They include product ions with $\mathrm{m} / \mathrm{z}$ of 226, 91, 105, 182, 528, and 119. Most abundant product ion was used in subsequent MRM transitions. Among those, product ion with $\mathrm{m} / \mathrm{z}$ of 226 demonstrated the highest intensity. In case of paclitaxel (Figure 2), six product ions with $\mathrm{m} / \mathrm{z}$ of $105,106,122,286$, 287, and 570 produced high intensities. Product ion with $\mathrm{m} / \mathrm{z}$ of 105 provided the highest intensity. Depending on the experimental conditions, docetaxel and paclitaxel tend to generate different adducts when ionized through ESI source. Some studies have reported the alkali-adducts (mainly sodium adduct $[\mathrm{M}+\mathrm{Na}]^{+}$) to be more intense (up to 5-fold) than protonated form $\left([\mathrm{M}+\mathrm{H}]^{+}\right)$[26] [37]. Although, there are reports that have exploited the protonated adduct 


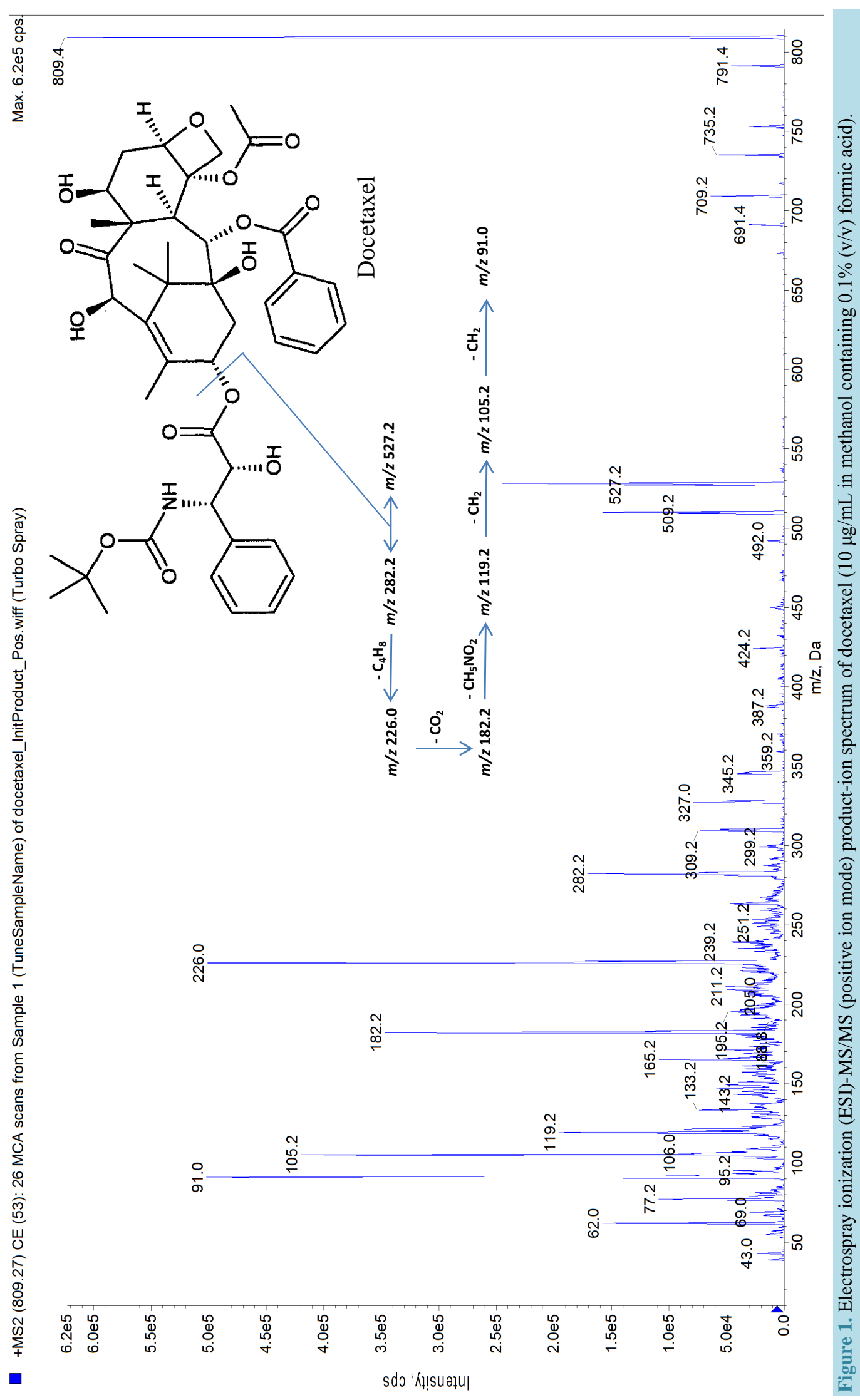


P. Rafiei et al.

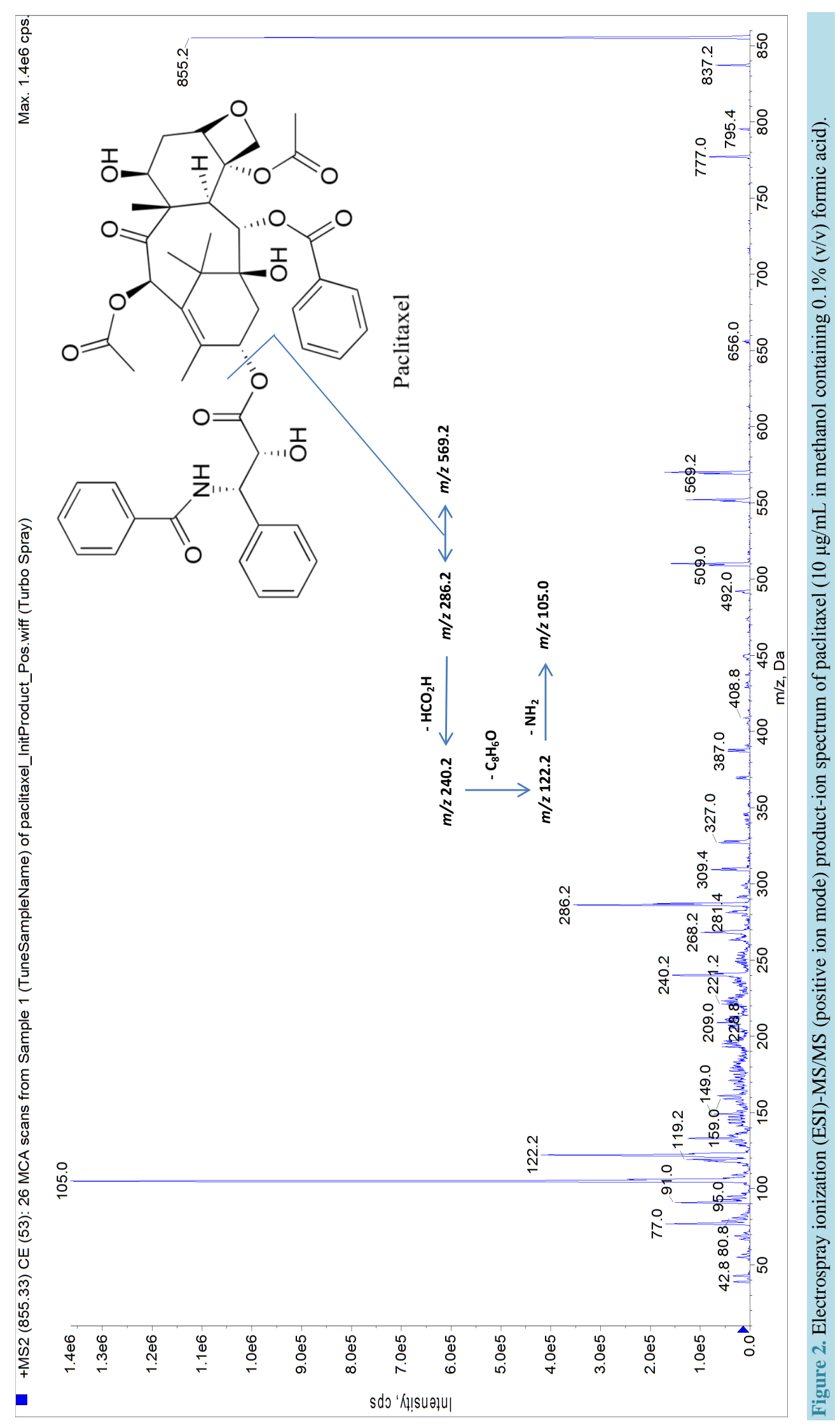


MRM transitions [38] [39] with good sensitivity. Taking into consideration the conditions used in this analysis method (e.g., isocractic elution), it was concluded that the protonated adduct could be the prominent ion. Consequently, in our study analysis was performed at the chosen MRM transitions in the presence of $0.1 \% \mathrm{v} / \mathrm{v}$ formic acid in methanol to obtain protonated adduct form the analyte and internal standard. Figure 3 demonstratestypical MRM Graphs of docetaxel and paclitaxel in various matrices.

\subsection{Method Performance}

For docetaxel solution in methanol, LOD and LOQ of the method were calculated to be $1.95 \mathrm{ng} / \mathrm{ml}$ and 3.9 $\mathrm{ng} / \mathrm{ml}$ respectively. This is while docetaxel in PLGA and PLGA-PEG nanoparticles demonstrated LOD and LOQ values equal to $62.5 \mathrm{ng} / \mathrm{ml}$ and $125 \mathrm{ng} / \mathrm{ml}$, respectively. The applied method covered a linearity range of $3.9-1000 \mathrm{ng} / \mathrm{ml}, 125$ - 16,000 ng/ml, and 125 - $8000 \mathrm{ng} / \mathrm{ml}$ of docetaxel concentration respectively in methanol, PLGA nanoparticles and PLGA-PEG nanoparticles with a 1/x weighting factor. The method was sensitive enough to help evaluate the amount of drug in the abovementioned matrices. In all cases, obtained daily standard curves demonstrated regression correlation coefficients $\left(\mathrm{R}^{2}\right)$ higher than 0.996 . Analysis of docetaxel in methanol at LLOQ concentration $(n=6)$ demonstrated an accuracy and coefficient of variation (CV\%) of less than $14.8 \%$ and $15.3 \%$ respectively. The evaluated within- and between-run variations of the docetaxel quantitation method in methanol (Table 1) demonstrated a CV\%s less than $12.3 \%$ between concentration sets (i.e., good precision). Analysis of docetaxel in PLGA nanoparticels at LLOQ concentration $(n=6)$ exhibited an accuracy and $\mathrm{CV} \%$ of less than $10.7 \%$ and $11.6 \%$ respectively. Within- and between-run variation studies of the docetaxel quantitation method in PLGA nanoparticles (Table 2) demonstrated CV\%s less than $10.5 \%$ between various concentrations (i.e., good precision). CV\%s for within- and between-run variation studies of docetaxel quantitation method in PLGA-PEG nanoparticles was calculated to be less than 10.94\% (Table 3). Analysis of docetaxel in PLGA-PEG nanoparticels at LLOQ concentration $(n=6)$ demonstrated an accuracy and CV\% of less than $13.42 \%$ and $13.07 \%$ respectively. In addition, back calculation of docetaxel quality control concentrations (accuracy) in methanol, PLGA nanoparticles, and PLGA-PEG nanoparticles exhibited values with acceptable deviation from actual concentrations (i.e., less than 15\% deviation).These results suggested that the present method could accurately and reproducibly (acceptable precision) measure docetaxel in methanol, PLGA nanoparticles, and PLGA-PEG nanoparticles.

\subsection{Nanoparticle Drug Loading and Encapsulation Efficiency}

Table 4 reports loading characteristics of different drug loaded nanoparticle formulations. It has been observed that increasing the drug concentration in organic solution increased the entrapment of docetaxel in PLGA nanoparticles. The reason could be attributed to interacting more number of drug molecules with PLGA when initial drug concentration is increased [15] [40]. However, increasing the concentration of drug from $0.25 \mathrm{mg} / \mathrm{ml}$ to $1.5 \mathrm{mg} / \mathrm{ml}$, the percentage of encapsulation efficiency demonstrates a descending trend (i.e., $47.76 \%$ to $37.25 \%$ ). Increment in initial preparation concentration of drug has resulted in increased drug loading in PLGA-PEG nanoparticle as well. Encapsulation efficiency of PLGA-PEG nanoparticles is also decreased from $96.1 \%$ to $59.3 \%$ when initial drug payload is increased from $0.25 \mathrm{mg} / \mathrm{ml} \mathrm{to} 1.5 \mathrm{mg} / \mathrm{ml}$. For both type of nanoparticles, it is proposed that initial high encapsulation efficiency (e.g., at $0.25 \mathrm{mg} / \mathrm{ml}$ ) might be due to high interactions of drug with polymer relative to the initial drug amount until polymer matrix gets saturated with drug molecules as more drug is used in the preparation procedure [15].

It should be emphasized that determining the amount of loaded drug inside polymeric matrix is a crucial step in characterization of nanoparticle. To date, docetaxel has been quantitatively assayed by means of different HPLC [15]-[17] [41] or UV [18] set-ups reporting different assay outcomes. for instance, Esmaeili et al. [12] reported their method LOD to be $50 \mathrm{ng} / \mathrm{ml}$ with a retention time around $12 \mathrm{~min}$. Musumeci and colleagues [13] determined docetaxel loading in PLGA nanoparticles at $0.7-37.9 \mu \mathrm{g} / \mathrm{ml}$ standard concentration range with a method sensitivity of $10 \mathrm{ng} / \mathrm{ml}$. in another study, elution period was $25 \mathrm{~min}$ and the retention time of drug was about 9 min [14]. In comparison, run and retention time of our assay were 2 and 0.6 minutes respectively which is far less than that obtained by other studies. This allows analysis of a high number of samples within an extremely short period of time with lowest level of expenses. Although there are several reports of docetaxel being quantitatively analysed in biological matrices (e.g., plasma) using rapid ESI-MS/MS method [21]-[30], yet quantitative analysis of docetaxel in polymeric matrices of PLGA and PLGA-PEG nanoparticles through direct injection to mass spectrometer has not been reported elsewhere. 


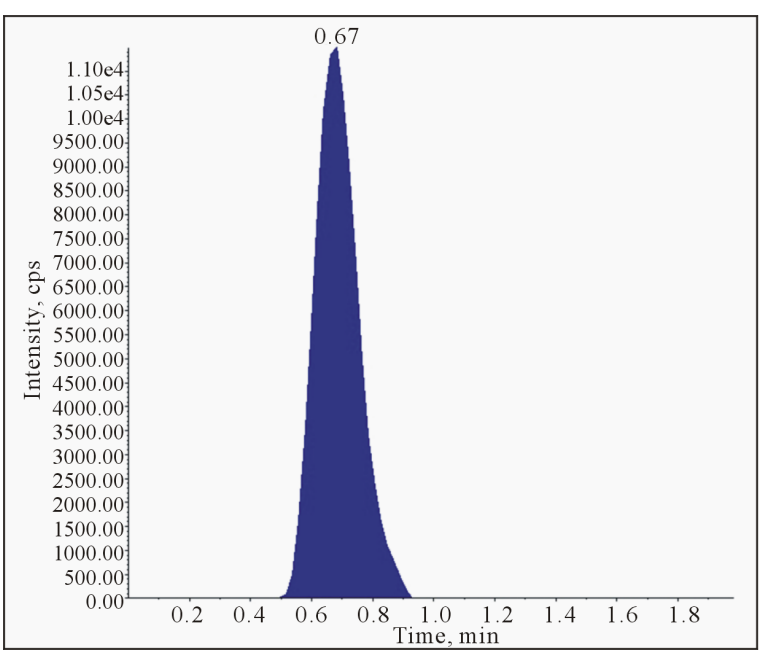

(a)

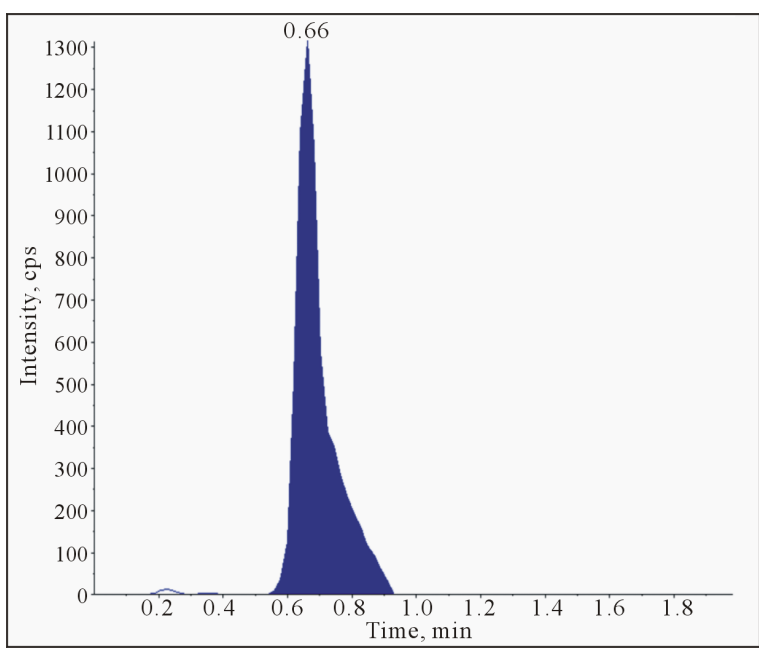

(c)

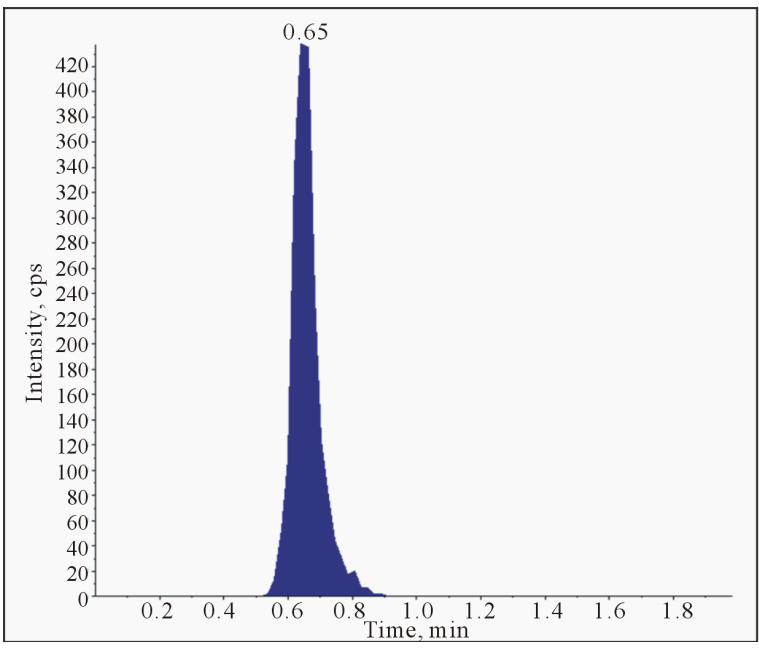

(e)

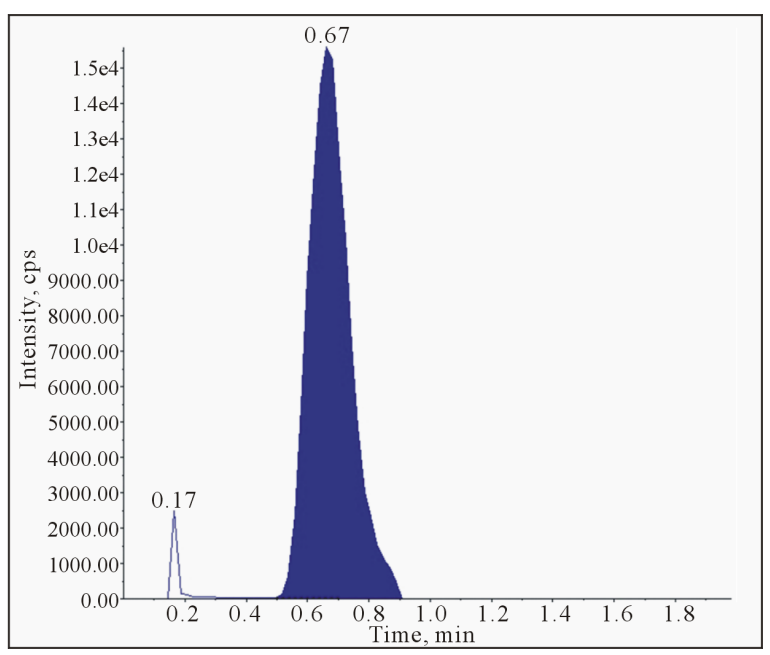

(b)

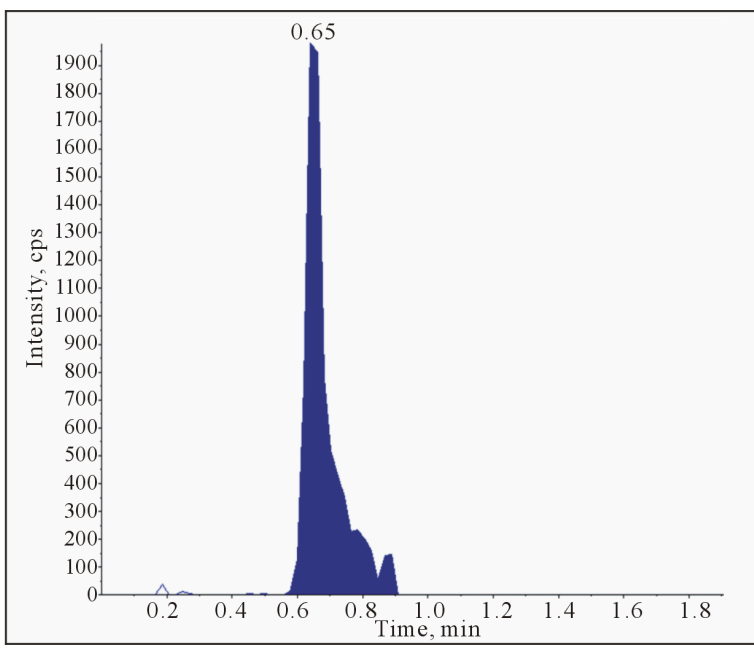

(d)

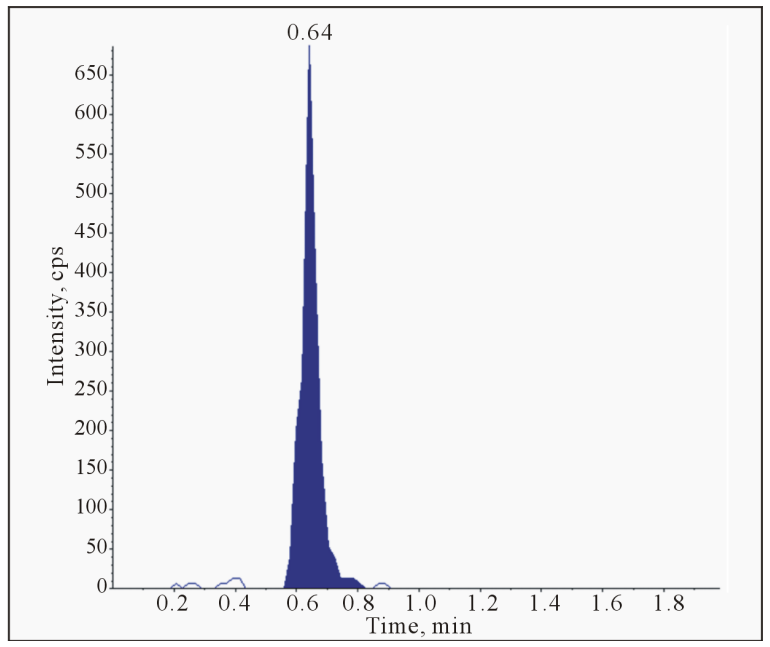

(f)

Figure 3. Typical MRM Graph of Docetaxel and internal standard (1000 ng/ml). (a) Docetaxel in methanol; (b) Paclitaxel in methanol; (c) Docetaxel in PLGA nanoparticles extract; (d) Paclitaxel in PLGA nanoparticles extract; (e) Docetaxel in PLGA-PEG nanoparticles extract; (f) Paclitaxel in PLGA-PEG nanoparticles extract. 
Table 1. Accuracy and precision of mass spectrometry analysis method for docetaxel quantitation in methanol. Data represents mean \pm standard deviation $(n=6)$. (CV\% = Coefficient of Variation)

\begin{tabular}{|c|c|c|c|c|c|c|}
\hline \multirow{2}{*}{$\begin{array}{c}\text { Actual } \\
\text { concentration }\end{array}$} & \multicolumn{3}{|c|}{ Within run variations } & \multicolumn{3}{|c|}{ Between run variations } \\
\hline & $\begin{array}{c}\text { Measured } \\
\text { concentration }\end{array}$ & CV\% & Accuracy (\%) & $\begin{array}{c}\text { Measured } \\
\text { concentration }\end{array}$ & CV\% & Accuracy (\%) \\
\hline $100 \mathrm{ng} / \mathrm{ml}$ & $99.8 \pm 8.7$ & 8.7 & $99.7 \pm 8.8$ & $100.6 \pm 5.9$ & 5.9 & $100.6 \pm 5.9$ \\
\hline $200 \mathrm{ng} / \mathrm{ml}$ & $197.7 \pm 10.5$ & 5.3 & $98.8 \pm 5.2$ & $207.2 \pm 9.2$ & 4.4 & $103.5 \pm 4.7$ \\
\hline $400 \mathrm{ng} / \mathrm{ml}$ & $371.2 \pm 16.7$ & 4.5 & $92.8 \pm 4.2$ & $370.3 \pm 45.5$ & 12.3 & $96.8 \pm 4.4$ \\
\hline $800 \mathrm{ng} / \mathrm{ml}$ & $756.8 \pm 70.5$ & 9.3 & $94.7 \pm 8.9$ & $826.2 \pm 53.6$ & 6.48 & $103.3 \pm 6.7$ \\
\hline
\end{tabular}

Table 2. Accuracy and precision of mass spectrometry analysis method for docetaxel quantitation in PLGA nanoparticles. Data represents mean \pm standard deviation $(n=6)$. ( $C V \%=$ Coefficient of Variation $)$

\begin{tabular}{ccccccc}
\hline \multirow{2}{*}{$\begin{array}{c}\text { Actual } \\
\text { concentration }\end{array}$} & \multicolumn{2}{c}{ Within-run variations } & \multicolumn{2}{c}{ Between-run variations } \\
\cline { 2 - 7 } & $\begin{array}{c}\text { Measured } \\
\text { concentration }\end{array}$ & CV\% & Accuracy (\%) & $\begin{array}{c}\text { Measured } \\
\text { concentration }\end{array}$ & CV\% & Accuracy (\%) \\
\hline $\mathbf{1 2 5 0} \mathbf{~ n g / m l}$ & $1351.7 \pm 81.8$ & 6.0 & $107.8 \pm 6.6$ & $1285 \pm 135.8$ & 10.5 & $102.8 \pm 11.0$ \\
$\mathbf{2 5 0 0} \mathbf{n g} / \mathbf{m l}$ & $2613.3 \pm 117.6$ & 4.5 & $104.6 \pm 4.6$ & $2550 \pm 215.4$ & 8.4 & $102.1 \pm 8.7$ \\
$\mathbf{5 0 0 0} \mathbf{~ n g / m l ~}$ & $5375 \pm 258.1$ & 4.8 & $107.6 \pm 5.2$ & $5373.3 \pm 294.7$ & 5.5 & $107.4 \pm 5.8$ \\
$\mathbf{1 0 0 0 0} \mathbf{~ n g / m l}$ & $10323.3 \pm 803.5$ & 7.8 & $103.2 \pm 8.0$ & $9811.7 \pm 810.1$ & 8.3 & $98.1 \pm 8.1$ \\
\hline
\end{tabular}

Table 3. Accuracy and precision of mass spectrometry analysis method for docetaxel quantitation in PLGA-PEG nanoparticles. Data represents mean \pm standard deviation $(n=6)$. (CV\% $=$ Coefficient of Variation $)$

\begin{tabular}{ccccccc}
\hline \multirow{2}{*}{$\begin{array}{c}\text { Actual } \\
\text { concentration }\end{array}$} & \multicolumn{2}{c}{ Within-run variations } & \multicolumn{2}{c}{ Between-run variations } \\
\cline { 2 - 7 } & $\begin{array}{c}\text { Measured } \\
\text { concentration }\end{array}$ & CV\% & Accuracy (\%) & $\begin{array}{c}\text { Measured } \\
\text { concentration }\end{array}$ & CV\% & Accuracy (\%) \\
\hline $\mathbf{6 2 5} \mathbf{~ n g / m l}$ & $651.7 \pm 51.5$ & 7.87 & $104.2 \pm 8.2$ & $641.8 \pm 46.1$ & 7.23 & $102.8 \pm 7.44$ \\
$\mathbf{1 2 5 0} \mathbf{~ n g / m l}$ & $1286.7 \pm 139.1$ & 10.58 & $103.0 \pm 10.9$ & $1375 \pm 85.2$ & 6.16 & $110.1 \pm 6.78$ \\
$\mathbf{2 5 0 0} \mathbf{~ n g / m l}$ & $2596.6 \pm 179.2$ & 6.84 & $103.8 \pm 7.1$ & $2588 \pm 195.7$ & 7.54 & $103.4 \pm 7.8$ \\
$\mathbf{5 0 0 0} \mathbf{~ n g / m l}$ & $5078.3 \pm 563.2$ & 10.94 & $101.4 \pm 11.1$ & $5230 \pm 562.9$ & 10.75 & $104.5 \pm 11.24$ \\
\hline
\end{tabular}

Table 4. Loading characteristics of various nanoparticle formulations. Data represents mean \pm standard deviation $(n=3)$. (EE = Encapsulation Efficiency, ${ }^{*}=\mu \mathrm{g}$ drug/mg polymer)

\begin{tabular}{|c|c|c|c|c|}
\hline Type/Preparation Conc. & Loaded amount ${ }^{*}$ & Drug loading (\%) & Yield (\%) & EE (\%) \\
\hline \multicolumn{5}{|l|}{ PLGA } \\
\hline $0.25 \mathrm{mg} / \mathrm{ml}$ & $1.2 \pm 0.03$ & $0.12 \pm 0.004$ & $39.76 \pm 4.56$ & $47.76 \pm 1.6$ \\
\hline $0.5 \mathrm{mg} / \mathrm{ml}$ & $2.06 \pm 0.08$ & $0.21 \pm 0.008$ & $31.66 \pm 4.04$ & $41.28 \pm 1.6$ \\
\hline $1 \mathrm{mg} / \mathrm{ml}$ & $4.52 \pm 0.43$ & $0.45 \pm 0.044$ & $56.33 \pm 11.15$ & $45.26 \pm 4.4$ \\
\hline $1.5 \mathrm{mg} / \mathrm{ml}$ & $5.58 \pm 0.24$ & $0.56 \pm 0.025$ & $64.88 \pm 8.13$ & $37.25 \pm 1.6$ \\
\hline \multicolumn{5}{|l|}{ PLGA-PEG } \\
\hline $0.25 \mathrm{mg} / \mathrm{ml}$ & $2.405 \pm 0.081$ & $0.240 \pm 0.008$ & $78.1 \pm 0.6$ & $96.1 \pm 3.2$ \\
\hline $0.5 \mathrm{mg} / \mathrm{ml}$ & $3.512 \pm 0.030$ & $0.3512 \pm 0.031$ & $84.5 \pm 7.1$ & $70.2 \pm 6.1$ \\
\hline $1 \mathrm{mg} / \mathrm{ml}$ & $6.229 \pm 0.082$ & $0.623 \pm 0.008$ & $56.2 \pm 12.3$ & $62.3 \pm 0.8$ \\
\hline $1.5 \mathrm{mg} / \mathrm{ml}$ & $8.890 \pm 0.101$ & $0.889 \pm 0.010$ & $85.7 \pm 3.6$ & $59.3 \pm 0.7$ \\
\hline
\end{tabular}




\section{Conclusion}

A simple and rapid ESI-MS/MS method for quantitative analysis of docetaxel in polymeric matrices of PLGA and PLGA-PEG nanoparticles has been developed and validated. Samples have been exposed to mass spectrometer through direct injections without the need for application of prior liquid chromatography. This has resulted in extreme reduction of run and retention time allowing the analysis of a high number of samples in a short period of time. Validation results demonstrated that an accurate, reproducible, and selective assay was obtained throughout a wide linear calibration range. Therefore, the developed method offers advantages over conventional ways of determining drug loading characteristics of nanoparticles with polymeric matrices such as HPLC or UV.

\section{Acknowledgements}

This work was funded by research grants from Natural Sciences and Engineering Research Council of Canada (NSERC) Discovery Grant and the Canadian Breast Cancer Foundation (CBCF). The authors report no declarations of interest.

\section{Conflict of Interest}

Authors declare no conflict of interest.

\section{References}

[1] Herbst, R.S. and Khuri, F.R. (2003) Mode of Action of Docetaxel-A Basis for Combination with Novel Anticancer Agents. Cancer Treatment Reviews, 29, 407-415. http://dx.doi.org/10.1016/S0305-7372(03)00097-5

[2] Takimoto, C. and Beeram, M. (2008) Microtubule Stabilizing Agents in Clinical Oncology, the Taxanes. In: Fojo, T., Ed., The Role of Microtubules in Cell Biology, Neurobiology, and Oncology, Human Press, Totowa, 395-419. http://dx.doi.org/10.1007/978-1-59745-336-3 16

[3] Hitt, R. and Rodríguez, C. (2011) Docetaxel. In: Schwab, M., Ed., Encyclopedia of Cancer, Springer-Verlag, Berlin, Heidelberg, 1148-1150.

[4] Zhao, P. and Astruc, D. (2012) Docetaxel Nanotechnology in Anticancer Therapy. ChemMedChem, 7, 952-972. http://dx.doi.org/10.1002/cmdc.201200052

[5] van Zuylen, L., Verweij, J. and Sparreboom, A. (2001) Role of Formulation Vehicles in Taxane Pharmacology. Investigational New Drugs, 19, 125-141. http://dx.doi.org/10.1023/A:1010618632738

[6] ten Tije, A.J., Verweij, J., Loos, W.J. and Sparreboom, A. (2003) Pharmacological Effects of Formulation Vehicles: Implications for Cancer Chemotherapy. Clinical Pharmacokinetics, 42, 665-685. http://dx.doi.org/10.2165/00003088-200342070-00005

[7] Blanco, E., Hsiao, A., Mann, A.P., Landry, M.G., Meric-Bernstam, F. and Ferrari, M. (2011) Nanomedicine in Cancer Therapy: Innovative Trends and Prospects. Cancer Science, 102, 1247-1252. http://dx.doi.org/10.1111/j.1349-7006.2011.01941.x

[8] Jabir, N.R., Tabrez, S., Ashraf, G.M., Shakil, S., Damanhouri, G.A. and Kamal, M.A. (2012) Nanotechnology-Based Approaches in Anticancer Research. International Journal of Nanomedicine, 7, 4391-4408. http://dx.doi.org/10.2147/IJN.S33838

[9] Dinarvand, R., Sepehri, N., Manoochehri, S., Rouhani, H. and Atyabi, F. (2011) Polylactide-co-Glycolide Nanoparticles for Controlled Delivery of Anticancer Agents. International Journal of Nanomedicine, 6, 877-895. http://dx.doi.org/10.2147/ijn.s18905

[10] Hamidi, M., Azadi, A. and Rafiei, P. (2006) Pharmacokinetic Consequences of Pegylation. Drug Delivery, 13, 399-409. http://dx.doi.org/10.1080/10717540600814402

[11] Hamidi, M., Rafiei, P. and Azadi, A. (2008) Designing PEGylated Therapeutic Molecules: Advantages in ADMET Properties. Expert Opinion on Drug Discovery, 3, 1293-1307. http://dx.doi.org/10.1517/17460441.3.11.1293

[12] Esmaeili, F., Dinarvand, R., Ghahremani, M.H., Ostad, S.N., Esmaily, H. and Atyabi, F. (2010) Cellular Cytotoxicity and in-Vivo Biodistribution of Docetaxelpoly(lactide-co-glycolide) Nanoparticles. Anticancer Drugs, 21, 43-52. http://dx.doi.org/10.1097/CAD.0b013e328331f934

[13] Musumeci, T., Ventura, C.A., Giannone, I., Ruozi, B., Montenegro, L., Pignatello, R. and Puglisi, G. (2006) PLA/PLGA Nanoparticles for Sustained Release of Docetaxel. International Journal of Pharmaceutics, 325, 172-179. http://dx.doi.org/10.1016/j.ijpharm.2006.06.023 
[14] Sanna, V., Roggio, A.M., Posadino, A.M., Cossu, A., Marceddu, S., Mariani, A., Alzari, V., Uzzau, S., Pintus, G. and Sechi, M. (2011) Novel Docetaxel-Loaded Nanoparticles Based on Poly(lactide-co-caprolactone) and Poly(lactide-coglycolide-co-caprolactone) for Prostate Cancer Treatment: Formulation, Characterization, and Cytotoxicity Studies. Nanoscale Research Letters, 6, 260. http://dx.doi.org/10.1186/1556-276X-6-260

[15] Senthilkumar, M., Mishra, P. and Jain, N.K. (2008) Long Circulating PEGylatedpoly(D,L-lactide-co-glycolide) Nanoparticulate Delivery of Docetaxel to Solid Tumors. Journal of Drug Targeting, 16, 424-435. http://dx.doi.org/10.1080/10611860802088598

[16] Danhier, F., Lecouturier, N., Vroman, B., Jérôme, C., Marchand-Brynaert, J., Feron, O. and Préat, V. (2009) PaclitaxelLoaded PEGylated PLGA-Based Nanoparticles: in Vitro and in Vivo Evaluation. Journal of Controlled Release, 133, 11-17. http://dx.doi.org/10.1016/j.jconrel.2008.09.086

[17] Cheng, J., Teply, B.A., Sherifi, I., Sung, J., Luther, G., Gu, F.X., Levy-Nissenbaum, E., Radovic-Moreno, A.F., Langer, R. and Farokhzad, O.C. (2007) Formulation of Functionalized PLGA-PEG Nanoparticles for in Vivo Targeted Drug Delivery. Biomaterials, 28, 869-876. http://dx.doi.org/10.1016/j.biomaterials.2006.09.047

[18] Dhankar, R., Rathee, P., Jain, A.K., Arora, S., Senthilkumar, M., Rath, G., Kumarsaxena, A., Sharma, P.R., Chashoo, G. and Goyal, A.K. (2011) HER-2 Targeted Immunonanoparticles for Breast Cancer Chemotherapy. Journal of Applied Pharmaceutical Science, 1, 132-139.

[19] López, L.Z., Pastor, A.A., Beitia, A., Manuel, J., Velilla, J.A. and Deiró, J.G. (2006) Determination of Docetaxel and Paclitaxel in Human Plasma by High-Performance Liquid Chromatography: Validation and Application to Clinical Pharmacokinetic Studies. Therapeutic Drug Monitoring, 28, 199-205. http://dx.doi.org/10.1097/01.ftd.0000189903.46802.1f

[20] Bermingham, S., O’Connor, R., Regan, F. and McMahon, G.P. (2010) Simultaneous Determination of Anthracyclines and Taxanes in Human Serum Using Online Sample Extraction Coupled to High Performance Liquid Chromatography with UV Detection. Journal of Separation Science, 33, 1571-1579. http://dx.doi.org/10.1002/jssc.201000026

[21] Parise, R.A., Ramanathan, R.K., Zamboni, W.C. and Egorin, M.J. (2003) Sensitive Liquid Chromatography-Mass Spectrometry Assay for Quantitation of Docetaxel and Paclitaxel in Human Plasma. Journal of Chromatography B, Analytical Technologies in the Biomedical and Life Sciences, 783, 231-236. http://dx.doi.org/10.1016/S1570-0232(02)00659-1

[22] Wang, L.Z., Goh, B.C., Grigg, M.E., Lee, S.C., Khoo, Y.M. and Lee, H.S. (2003) A Rapid and Sensitive Liquid Chromatography/Tandem Mass Spectrometry Method for Determination of Docetaxel in Human Plasma. Rapid Communications in Mass Spectrometry, 17, 1548-1552. http://dx.doi.org/10.1002/rcm.1091

[23] Hou, W., Watters, J.W. and McLeod, H.L. (2004) Simple and Rapid Docetaxel Assay in Plasma by Protein Precipitation and High-Performance Liquid Chromatography-Tandem Mass Spectrometry. Journal of Chromatography B, Analytical Technologies in the Biomedical and Life Sciences, 804, 263-267. http://dx.doi.org/10.1016/j.jchromb.2004.01.021

[24] Mortier, K.A., Renard, V., Verstraete, A.G., Van Gussem, A., Van Belle, S. and Lambert, W.E. (2005) Development and Validation of a Liquid Chromatography-Tandem Mass Spectrometry Assay for the Quantification of Docetaxel and Paclitaxel in Human Plasma and Oral Fluid. Analytical Chemistry, 77, 4677-4683. http://dx.doi.org/10.1021/ac0500941

[25] Guitton, J., Cohen, S., Tranchand, B., Vignal, B., Droz, J.P., Guillaumont, M., Manchon, M. and Freyer, G. (2005) Quantification of Docetaxel and Its Main Metabolites in Human Plasma by Liquid Chromatography/Tandem Mass Spectrometry. Rapid Communications in Mass Spectrometry, 19, 2419-2426. http://dx.doi.org/10.1002/rcm.2072

[26] Huang, Q., Wang, G.J., Sun, J.G., Hu, X.L., Lu, Y.H. and Zhang, Q. (2007) Simultaneous Determination of Docetaxel and Ketoconazole in Rat Plasma by Liquid Chromatography/Electrospray Ionization Tandem Mass Spectrometry. Rapid Communications in Mass Spectrometry, 21, 1009-1018. http://dx.doi.org/10.1002/rcm.2903

[27] Gustafson, D.L., Long, M.E., Zirrolli, J.A., Duncan, M.W., Holden, S.N., Pierson, A.S. and Eckhardt, S.G. (2003) Analysis of Docetaxel Pharmacokinetics in Humans with the Inclusion of Later Sampling Time-Points Afforded by the Use of a Sensitive Tandem LCMS Assay. Cancer Chemotherapy and Pharmacology, 52, 159-166. http://dx.doi.org/10.1007/s00280-003-0622-z

[28] Baker, S.D., Sparreboom, A. and Verweij, J. (2006) Clinical Pharmacokinetics of Docetaxel: Recent Developments. Clinical Pharmacokinetics, 45, 235-252. http://dx.doi.org/10.2165/00003088-200645030-00002

[29] Kuppens, I.E., van Maanen, M.J., Rosing, H., Schellens, J.H. and Beijnen. J.H. (2005) Quantitative Analysis of Docetaxel in Human Plasma Using Liquid Chromatography Coupled with Tandem Mass Spectrometry. Biomedical Chromatography, 19, 355-361. http://dx.doi.org/10.1002/bmc.457

[30] Sparreboom, A., Zhao, M., Brahmer, J.R., Verweij, J. and Baker, S.D. (2002) Determination of the Docetaxel Vehicle, Polysorbate 80, in Patient Samples by Liquid Chromatography-Tandem Mass Spectrometry. Journal of Chromatography B, Analytical Technologies in the Biomedical and Life Sciences, 773, 183-190. 
http://dx.doi.org/10.1016/S1570-0232(02)00167-8

[31] Ito, Y., Goto, T., Oka, H., Matsumoto, H., Miyazaki, Y., Takahashi, N. and Nakazawa, H. (2003) Simple and Rapid Determination of Thiabendazole, Imazalil, and O-Phenylphenol in Citrus Fruit Using Flow-Injection Electrospray Ionization Tandem Mass Spectrometry. Journal of Agricultural and Food Chemistry, 51, 861-866. http://dx.doi.org/10.1021/jf020809q

[32] Song, F., El-Demerdash, A., Lee, S.J. and Smith, R.E. (2012) Fast Screening of Lovastatin in Red Yeast Rice Products by Flow Injection Tandem Mass Spectrometry. Journal of Pharmaceutical and Biomedical Analysis, 57, 76-81. http://dx.doi.org/10.1016/j.jpba.2011.08.039

[33] Zhou, H., Tai, Y., Sun, C. and Pan, Y. (2005) Rapid Identification of Vinca Alkaloids by Direct-Injection Electrospray Ionisation Tandem Mass Spectrometry and Confirmation by High-Performance Liquid Chromatography-Mass Spectrometry. Phytochemical Analysis, 16, 328-333. http://dx.doi.org/10.1002/pca.852

[34] Carducci, C., Santagata, S., Leuzzi, V., Carducci, C., Artiola, C., Giovanniello, T., Battini, R. and Antonozzi, I. (2006) Quantitative Determination of Guanidinoacetate and Creatine in Dried Blood Spot by Flow Injection Analysis Electrospray Tandem Mass Spectrometry. Clinica Chimica Acta, 364, 180-187. http://dx.doi.org/10.1016/j.cca.2005.06.016

[35] Peer, C.J., Clay, D.J., Glover, H.L., Renninger, K.L., Kraner, J.C. and Callery, P.S. (2008) Direct Injection Mass Spectrometric Confirmation of Multiple Drugs in Overdose Cases from Postmortem Blood Using Electrospray Ionization-Tandem Mass Spectrometry and MS(3). Journal of Analytical Toxicology, 32, 709-714. http://dx.doi.org/10.1093/jat/32.8.709

[36] Peer, C.J., Shakleya, D.M., Younis, I.R., Kraner, J.C. and Callery, P.S. (2007) Direct-Injection Mass Spectrometric Method for the Rapid Identification of Fentanyl and Norfentanyl in Postmortem Urine of Six Drug-Overdose Cases. Journal of Analytical Toxicology, 31, 515-521. http://dx.doi.org/10.1093/jat/31.8.515

[37] Grozav, A.G., Hutson, T.E., Zhou, X., Bukowski, R.M., Ganapathi, R. and Xu, Y. (2004) Rapid Analysis of Docetaxel in Human Plasma by Tandem Mass Spectrometry with On-Line Sample Extraction. Journal of Pharmaceutical and Biomedical Analysis, 36, 125-131. http://dx.doi.org/10.1016/j.jpba.2004.05.014

[38] Yamaguchi, H., Fujikawa, A., Ito, H., Tanaka, N., Furugen, A., Miyamori, K., Takahashi, N., Ogura, J., Kobayashi, M., Yamada, T., Mano, N. and Iseki, K. (2012) A Rapid and Sensitive LC/ESI-MS/MS Method for Quantitative Analysis of Docetaxel in Human Plasma and Its Application to a Pharmacokinetic Study. Journal of Chromatography B, Analytical Technologies in the Biomedical and Life Sciences, 893-894, 157-161. http://dx.doi.org/10.1016/j.jchromb.2012.02.003

[39] Corona, G., Elia, C., Casetta, B., Frustaci, S. and Toffoli, G. (2011) High-Throughput Plasma Docetaxel Quantification by Liquid Chromatography-Tandem Mass Spectrometry. Clinica Chimica Acta, 412, 358-364. http://dx.doi.org/10.1016/j.cca.2010.11.010

[40] Keum, C.G., Noh, Y.W., Baek, J.S., Lim, J.H., Hwang, C.J., Na, Y.G., Shin, S.C. and Cho, C.W. (2011) Practical Preparation Procedures for Docetaxel-Loaded Nanoparticles Using Polylactic Acid-Co-Glycolic Acid. International Journal of Nanomedicine, 6, 2225-2234. http://dx.doi.org/10.2147/IJN.S24547

[41] Shi, W., Zhang, Z.J., Yuan, Y., Xing, E.M., Qin, Y., Peng, Z.J., Zhang, Z.P. and Yang, K.Y. (2013) Optimization of Parameters for Preparation of Docetaxel-Loaded PLGA Nanoparticles by Nanoprecipitation Method. Journal of Huazhong University of Science and Technology, 33, 754-758. http://dx.doi.org/10.1007/s11596-013-1192-x 
Scientific Research Publishing (SCIRP) is one of the largest Open Access journal publishers. It is currently publishing more than 200 open access, online, peer-reviewed journals covering a wide range of academic disciplines. SCIRP serves the worldwide academic communities and contributes to the progress and application of science with its publication.

Other selected journals from SCIRP are listed as below. Submit your manuscript to us via either submit@scirp.org or Online Submission Portal.
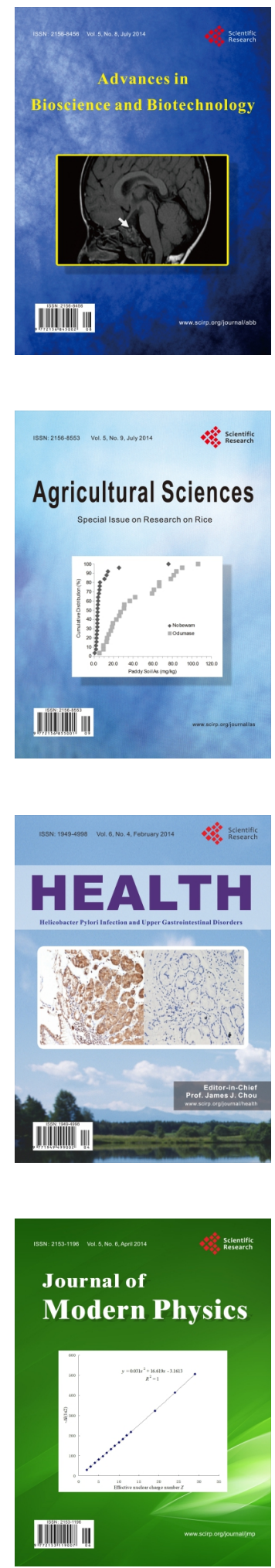
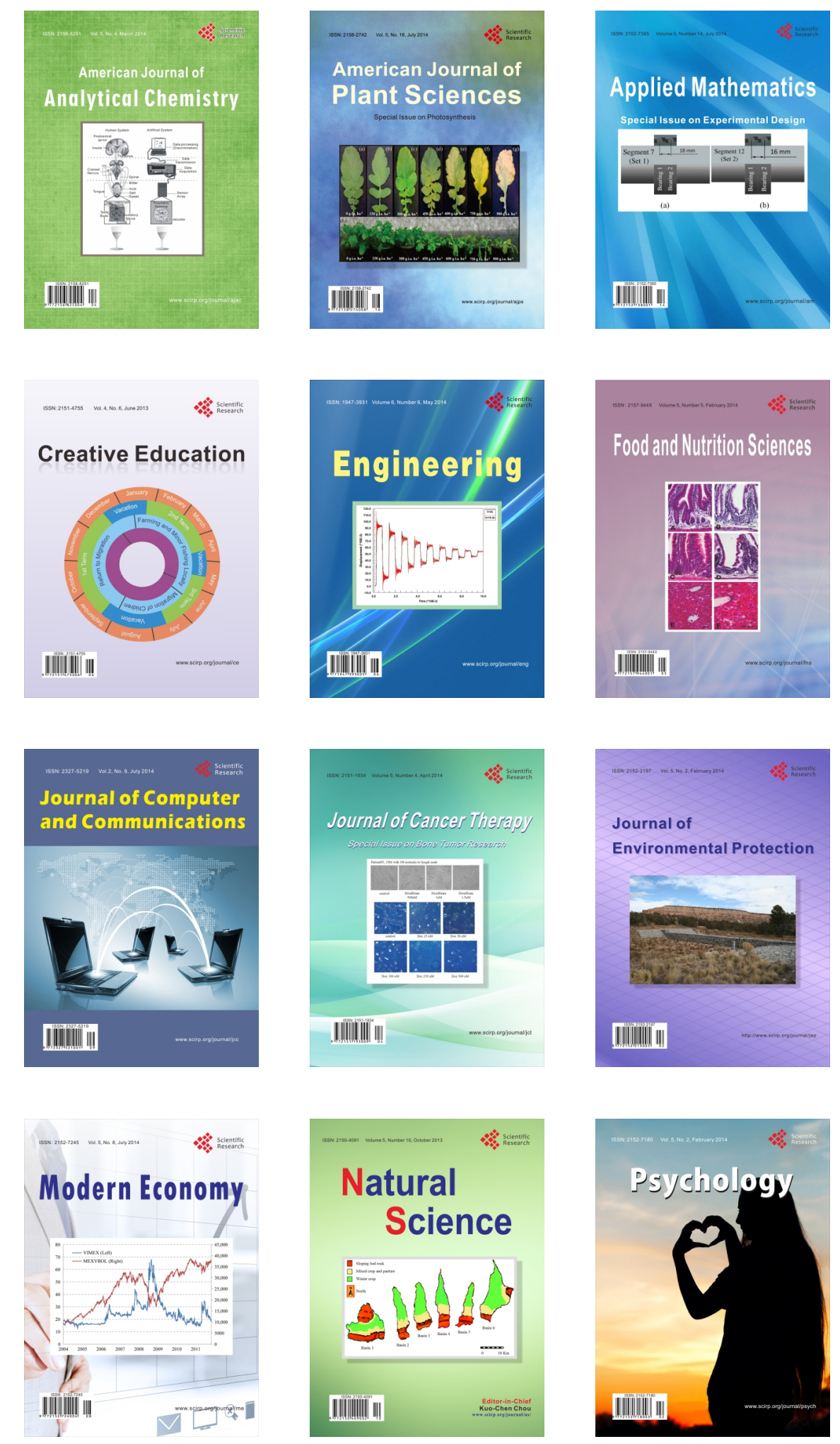